\title{
Bricqueville-sur-Mer - Le Vieux Château
}

n³505

\section{Daniel Hélye}

\section{(2) OpenEdition}

1 Journals

Édition électronique

URL : http://journals.openedition.org/adlfi/16704

ISSN : 2114-0502

Éditeur

Ministère de la culture

Référence électronique

Daniel Hélye, "Bricqueville-sur-Mer - Le Vieux Château », ADLFI. Archéologie de la France - Informations [En ligne], Basse-Normandie, mis en ligne le 26 février 2016, consulté le 01 mai 2019. URL : http:// journals.openedition.org/adlfi/16704

Ce document a été généré automatiquement le 1 mai 2019.

(c) Ministère de la Culture et de la Communication, CNRS 


\title{
Bricqueville-sur-Mer - Le Vieux Château
}

$n^{\circ} 3505$

\author{
Daniel Hélye
}

Lien Atlas (MCC) :

http://atlas.patrimoines.culture.fr/atlas/trunk/index.php?

ap_theme=DOM_2.01.02\&ap_bbox=-1.567;48.903;-1.474;48.934

1 Le sondage réalisé en 2012 à l'intérieur de la tour dite «le Vieux Château » n'apporta aucun élément probant permettant d'avancer des éléments chronologiques relatifs à la construction de la tour et sur la construction du puits creusé à l'intérieur et qui détruisit la quasi-totalité de la stratigraphie.

2 La campagne de 2013 a été axée sur le bâti et l'environnement immédiat de la tour, les matériaux utilisés et la méthode employée pour sa construction.

\section{Les relevés topographiques}

Les photos aériennes ainsi que les anciens cadastres laissaient entrevoir d'anciennes limites de parcelles aujourd'hui disparues, du fait du remembrement ainsi que des anomalies dans la végétation. Les relevés topographiques confirmèrent l'existence d'une plate-forme d'environ $500 \mathrm{~m}^{2}$ pouvant très bien correspondre à l'emplacement d'un ensemble avec un habitat seigneurial, des communs, le tout clos de douves et de fossés. Les comblements successifs nivelèrent le sol à tel point qu'il est impossible d'en délimiter les contours avec précision. Les principales périodes de destructions se situent entre la fin du $\mathrm{XVI}^{\mathrm{e}} \mathrm{s}$ et la première moitié du XIX $\mathrm{e}$., époques où le "château " servit à la fois de carrière de pierres pour la réfection des chemins vicinaux et de matériaux de construction pour les habitants des environs. Seul l'intérieur de la tour a fait l'objet d'un rehaussement significatif par un apport de terre végétale. Les dénivelés sont faibles, l'amplitude maximum n'excède pas 70 centimètres. 


\section{Sondage sud-ouest}

4 Ce sondage suggère la probable existence d'une petite douve ceinturant la chemise de la tour. Cette douve n'est repérée avec certitude qu'en un seul endroit. Sa largeur semble modeste puisqu'elle n'excède pas les 3,5 m. Les douves sont entourées par un petit muret de contrescarpe qui repose sur d'anciennes maçonneries éboulées. Cette assise insolite lui assure d'une part une bonne stabilité, et d'autre part évite au constructeur d'avoir à recreuser des fondations.

5 Le diagnostic réalisé ne permet pas dans l'état actuel de nos recherches de savoir si la contrescarpe épouse réellement la forme circulaire de la tour et maintient partout le même écartement. Les niveaux inférieurs contiennent d'importants blocs granitiques provenant d'ouvertures, portes et fenêtres tombées dans les douves lors de la démolition de la tour.

\section{Sondage ouest}

6 L'ouverture d'une petite tranchée à l'extérieur ouest de la tour fait suite aux travaux de 2012 qui avaient révélé l'existence d'un conduit d'évacuation. La campagne 2013 a confirmé l'existence de latrines à conduit en biais avec rejet direct dans les douves. La conception originale de cette construction pour une résidence au demeurant assez modeste démontre tout le soin apporté par le seigneur à l'hygiène à l'intérieur de sa résidence. Le modèle n'est peut-être pas unique en Normandie, il demeure cependant extrêmement rare dans le département de la Manche.

7 La stratigraphie se limite à trois niveaux de remblais. Le mobilier se limite au grès bien connu du Domfrontais et à deux fragments de pavés vernissés. Aucun élément de datation n'a été retrouvé dans cette zone.

8 S'il est encore prématuré de définir avec précision l'usage et la position de cette tour dans un ensemble aristocratique beaucoup plus vaste, l'hypothèse d'une guette ou donjon isolé semble la plus probable.

\section{INDEX}

Index géographique : Basse-Normandie, Manche (50), Bricqueville-sur-Mer

Mots-clés : bâti, douve, contrescarpe, tour, latrines

operation Sondage (SD)

Index chronologique : Indéterminée 
AUTEURS

DANIEL HÉLYE

BEN 